Review

\title{
Disruption of the Gut Microbiome: Clostridium difficile Infection and the Threat of Antibiotic Resistance
}

\author{
Priscilla A. Johanesen, Kate E. Mackin, Melanie L. Hutton, Milena M. Awad, Sarah Larcombe, \\ Jacob M. Amy and Dena Lyras * \\ Infection and Immunity Program, Monash Biomedicine Discovery Institute and \\ Department of Microbiology, Monash University, Clayton 3800, Australia; \\ E-Mails: priscilla.johanesen@monash.edu (P.A.J.); kate.mackin@monash.edu (K.E.M.); \\ melanie.hutton@monash.edu (M.L.H.); milena.awad@monash.edu (M.M.A.); \\ sarah.larcombe@monash.edu (S.L.); jacob.amy@monash.edu (J.M.A.) \\ * Author to whom correspondence should be addressed; E-Mail: dena.lyras@monash.edu; \\ Tel.: +61-3-9902-9155; Fax: +61-3-9902-9222.
}

Academic Editor: Jonathan Iredell

Received: 28 August 2015 / Accepted: 10 December 2015 / Published: 21 December 2015

\begin{abstract}
Clostridium difficile is well recognized as the leading cause of antibiotic-associated diarrhea, having a significant impact in both health-care and community settings. Central to predisposition to $C$. difficile infection is disruption of the gut microbiome by antibiotics. Being a Gram-positive anaerobe, $C$. difficile is intrinsically resistant to a number of antibiotics. Mobile elements encoding antibiotic resistance determinants have also been characterized in this pathogen. While resistance to antibiotics currently used to treat $C$. difficile infection has not yet been detected, it may be only a matter of time before this occurs, as has been seen with other bacterial pathogens. This review will discuss $C$. difficile disease pathogenesis, the impact of antibiotic use on inducing disease susceptibility, and the role of antibiotic resistance and mobile elements in $C$. difficile epidemiology.
\end{abstract}

Keywords: Clostridium difficile; antibiotic-associated diarrhea; microbiome; microbiota; antibiotic resistance; mobile genetic elements 


\section{Antibiotic-Associated Diarrhea-Disruption of the Gut Microbiome}

The human gut microbiome is established shortly after birth and plays an important role in human health and disease. It consists of a complex community of microorganisms that varies between individuals. Dysbiosis of the gut microbiota is associated with numerous diseases including gastrointestinal disorders such as celiac disease and inflammatory bowel disease, as well as other systemic diseases including obesity, diabetes and rheumatoid arthritis [1,2]. Of particular concern is the use of broad-spectrum antibiotics, which, in addition to treating primary infection, profoundly affect the host microbiome, disrupting the protective host microbiota. In the gastrointestinal tract, this state of dysbiosis leaves patients susceptible to infection by opportunistic bacterial pathogens, leading to a spectrum of infectious diarrheal diseases known as antibiotic-associated diarrhea (AAD) [3]. Pathogens associated with AAD include Clostridium difficile, Clostridium perfringens, Staphylococcus aureus and Klebsiella oxytoca, however, in many AAD cases, no infectious agent can be determined [3]. While antibiotic use is the primary risk factor for infectious AAD the specific antibiotics that result in disease differ depending on the causative organism. A complicating factor of AAD is that treatment typically involves additional antibiotic administration, which prevents restoration of the protective gut microbiota, thereby prolonging disease or facilitating relapse [4]. In addition to antibiotics, the use of other medications such as acid-reducing proton-pump inhibitors is associated with a predisposition to AAD [5-7]. This predisposition may be a result of reduced gastric acidity, allowing bacteria to survive stomach transit [8], or result in reduced immune cell function, allowing pathogen survival [9-11].

Overall, AAD rates in pediatric and adult populations are similar [3]. However, in the case of C. difficile, which is the most common causative agent of infectious $\mathrm{AAD}$, age is a major risk factor for the development of infection, with disease incidence and severity escalating as age increases [12]. Other AAD risk factors relate primarily to a reduction in health status of patients prior to disease onset with many of these risk factors being more common in elderly people. C. difficile infection (CDI) is primarily a hospital-acquired disease identified in elderly and immunocompromised patients, however, community-associated CDI has emerged in the last decade, and infection in people previously thought to be low-risk, such as children and pregnant women, has increased [13-16]. The changing epidemiology of this disease, coupled with the emergence of strains that cause more severe infections, has prompted the Centre for Disease Control and Prevention (CDC) to define C. difficile as an urgent threat [17]. Unsurprisingly, research efforts internationally remain focused on $C$. difficile as the main etiologic agent of AAD.

\section{C. difficile Infection and Pathogenesis}

C. difficile is a Gram-positive, spore-forming anaerobic pathogen that is responsible for $10 \%-25 \%$ of AAD cases [18]. The spectrum of disease caused by $C$. difficile commonly ranges from asymptomatic carriage or mild to moderate diarrhea with abdominal cramping to profuse diarrhea and severe abdominal pain $[19,20]$. Less commonly, more severe conditions such as pseudomembranous colitis, toxic megacolon or colonic perforation can occur, sometimes leading to death [19-21]. The antibiotics most commonly associated with CDI include clindamycin, the cephalosporin family, broad-spectrum penicillins and fluoroquinolones [22]. 
C. difficile is acquired via the fecal-oral route of transmission through ingestion of the bacterial spore of the bacterium. Upon reaching the anaerobic gut niche of susceptible patients, the spores germinate into metabolically active vegetative cells that produce active toxins and induce disease in the colon [23]. The best characterized virulence determinants are the two major exotoxins, Toxin A (TcdA) and Toxin B (TcdB). These toxins inactivate Rho family GTPases, leading to disorganization of the actin cytoskeleton, cell-rounding and apoptosis of intoxicated cells [20,24]. Toxin-mediated cell death leads to the impairment of cellular tight junctions, which increases intestinal membrane permeability and facilitates inflammation [20]. Some strains of $C$. difficile produce a third toxin, CDT (C. difficile transferase), which may also be involved in the disease process. CDT is a binary actin-ADP-ribosylating toxin that catalyses irreversible ADP ribosylation of monomeric actin, resulting in disruption to the host cell cytoskeleton [25]. Strains capable of producing binary toxin have been associated with more severe disease in humans [26], however, the role of this toxin in disease is not clear. While the toxins produced by $C$. difficile are important for disease, other factors are also required for colonization, immune evasion and growth in the host. These factors include fibronectin binding protein, the heat-shock protein GroEL, type IV fimbriae, the surface layer (S-layer), extracellular proteases and flagella $[23,26]$.

\section{C. difficile Spores-Transmission and Recurrence of Disease}

Central to host infection are $C$. difficile spores, which promote host-to-host transmission and disease recurrence within both hospitals and the community [27]. Disease relapse rates are often high with up to $30 \%$ of patients experiencing recurrence of infection with the same strain or with a different $C$. difficile strain [28-33]. Spores are the metabolically dormant and environmentally hardy form of the bacterium, exhibiting resistance to extreme temperatures, desiccation, aerobic conditions and to many disinfectants and hospital cleaning agents [34-37]. These attributes make spores difficult to eradicate from contaminated hospitals and allows them to persist within this setting for substantial time periods [38].

Spores can be transmitted from host-to-host or via the contamination of abiotic surfaces [34]. Once ingested the spore traverses the gut where cholate-containing bile salts in the intestine initiate germination [39]. The use of cecal and small intestinal extracts isolated from mice in which the host microbiome was disrupted by antibiotics was shown to enhance the germination of $C$. difficile spores, since primary bile salts are more abundant in these preparations than the secondary bile salts that are known to inhibit the growth of $C$. difficile [40]. The natural microbiota plays an important role in this stage of infection since microorganisms such as Clostridium scindens, which is involved in secondary bile acid synthesis, provide resistance to $C$. difficile infection in mice [41]. Although $C$. difficile-mediated disease is toxin dependent, spores are a critical component of the life cycle of this bacterium. Indeed, in mice, antibiotic treatment induces a supershedder state, with excretion of high spore numbers and concomitant heightened disease transmission observed, which may also occur in patients undergoing antibiotic treatment in a clinical setting [42].

\section{Antibiotic Use and Resistance in C. difficile}

Antibiotic use and resistance is linked closely to the development of CDI and the persistence of C. difficile as a disease-causing agent. Pseudomembranous colitis associated with the use of antibiotics, in particular clindamycin, was first reported in the 1970s [43]. Subsequent research identifying C. difficile as 
a causative agent [44-46] noted that strains isolated from the feces of patients were resistant to a diverse range of antibiotics including $\beta$-lactams (penicillins and cephalosporins), aminoglycosides, lincomycin, tetracyclines, and erythromycin [46]. In the 1980s cephalosporins and broad spectrum penicillins replaced clindamycin as major pre-disposing factors to $C$. difficile infection [47-49]. While pseudomembranous colitis continued to remain a significant healthcare issue for many years the early 2000s marked a significant turning point with the highly publicized global emergence of the so-called "hypervirulent" C. difficile strains, in particular type BI/NAP1/027 [50-53]. Notably, these strains had developed fluoroquinolone resistance (FQR), most likely due to overuse of this antibiotic. Genome sequence analysis of a global collection of isolates identified two genetically distinct lineages that were responsible for the epidemics, FQR1 and FQR2, both of which had identical mutations in DNA gyrase subunit A $($ gyrA $)$ [54]. While often associated with the "hypervirulent" strains, fluoroquinolone resistance has been documented in other strain types and is not unique to ribotype 027 . In these studies, mutations in the gyrA and/or gyrB genes have also been identified in non-ribotype 027 fluoroquinolone resistant isolates of $C$. difficile [55-57].

Investigations into $C$. difficile antibiotic resistance have revealed that multiple mechanisms for the acquisition of antibiotic resistance exist, including transposons, mobile genetic elements and various genetic mutations. Antibiotic resistance phenotypes in $C$. difficile associated with mutations in housekeeping genes have been described for antibiotics that are not commonly used in the treatment of CDI, such as fluoroquinolones. In these instances it is likely that selective pressure in vivo has resulted in the development of antibiotic resistance. This has been observed with antibiotics belonging to the rifamycin class of antibiotics, in particular rifampin and rifaximin, which were previously investigated as alternative CDI therapies [58], with resistance resulting from mutations in the $\beta$ subunit of bacterial RNA polymerase, rров [59-61]. Resistance has also been observed in $C$. difficile strains isolated from patients treated with fusidic acid [62], with mutations occurring in the fus $A$ gene encoding a protein elongation factor [63].

A significant proportion of the $C$. difficile genome consists of a large number of mobile elements including putative conjugative and mobilizable transposons and bacteriophages [54,64-66]. While plasmids are known to play an important role in the transfer of antibiotic resistance in many human pathogens $[67,68]$ and in other clostridia $[69,70]$, plasmids encoding antibiotic resistance in C. difficile have not been described. Transferable antibiotic resistance associated with tetracycline, clindamycin and erythromycin in $C$. difficile was first reported in the 1980s [71-74] and was found to occur via horizontal gene transfer of integrated chromosomal elements such as mobilizable and conjugative transposons $[75,76]$. The use of tetracyclines is not a common predisposing factor in CDI [12], however, resistance to this class of antibiotics is common in C. difficile. Tetracycline resistance in this bacterium is mediated by a ribosomal protection mechanism encoded by the $\operatorname{tet}(\mathrm{M})$ gene and is associated with a conjugative transposon, Tn5397 [74,76]. Tn5397 is closely related to the well characterized conjugative transposon Tn916, first identified in Enterococcus faecalis and subsequently found in many Gram-positive and Gram-negative bacteria, including many important bacterial pathogens [77,78]. Tn5397 functionally differs from Tn916 in its integration/excision module and also contains a group II intron [76]. Transposition of Tn5397 occurs between C. difficile strains, Bacillus subtilis [79], E. faecalis [80] and oral Streptococcus species [81]. C. difficile may therefore act as a donor of transferrable antibiotic resistance determinants to other bacterial genera and species that occupy the same environmental or host niche. 
In addition to Tn5397, experimental and in silico genome analysis has shown that $C$. difficile carries a number of other Tn916-like transposons, some of which encode tetracycline resistance determinants and some that carry other accessory genes [64,82-84]. Notably, some of these Tn916-like derivatives encode genes predicted to encode resistance to erythromycin and $\beta$-lactams [82].

C. difficile resistance to the MLS $\mathrm{B}$ family of antibiotics, including clindamycin and erythromycin, is widespread and typically conferred by the $\operatorname{erm}(\mathrm{B})$ gene, which encodes a 23S RNA methylase [85]. Importantly, $\operatorname{erm}(\mathrm{B})$ was found to be associated with epidemics caused by clindamycin-resistant $C$. difficile isolates in four hospitals in the USA in the late 1980s and early 1990s [86]. In strain $630 \mathrm{erm}(\mathrm{B})$ is located on the mobilizable element, Tn5398 [73,85]. Variations of this element are abundant in C. difficile with up to 17 different genetic organizations of Tn5398-like derivatives described [57,75,87]. Recently erm(B) was also found to be present on the Tn916-like conjugative transposon, Tn6194 [88], which can be transferred between $C$. difficile strains and also to E. faecalis [89]. Although erm(B) primarily appears to be transferred via cell-to-cell contact through conjugative DNA transfer of transposons, a phage-mediated transduction process that may also facilitate the dissemination of this resistance gene has also been observed [90]. This can be seen in the case of Tn6215, a novel $13 \mathrm{~kb}$ erm(B)-carrying novel mobilizable transposon that can be transferred to recipient cells via a conjugation-like mechanism but is also able to be transduced by phage ФC2 [90]. The complexity of erm(B)-carrying elements, their multiple modes of dissemination and ability to transfer within $C$. difficile strains and to bacteria belonging to other genera highlights their genetic fluidity and the potential for antibiotic resistance gene transmission to occur amongst bacteria that share the same niche.

Chloramphenicol resistance has also been identified in $C$. difficile, despite this antibiotic not being used as a treatment for CDI. This resistance phenotype is not as common in C. difficile as tetracycline or erythromycin resistance, but is similarly encoded on a mobile element. Chloramphenicol resistance in $C$. difficile is mediated by the catP gene, which encodes a chloramphenicol acetyltransferase enzyme [91]. The cat $P$ gene is chromosomally located in $C$. difficile and is encoded within the mobilizable transposons Tn $4453 a$ and Tn4453b. These elements are closely related to the catP mobilizable transposon Tn4451, located on the conjugative plasmid pIP401 in C. perfringens [92], and collectively form the Tn4451/3 family of mobilizable transposons. DNA sequence analysis has provided evidence that Tn4451/3-like elements can be found in various strains of $C$. difficile and also in commensal human intestinal bacteria, including Clostridium nexile and Coprococcus species [93]. In two C. difficile-associated elements the chloramphenicol resistance genes have been replaced by genes putatively encoding aminoglycoside resistance or transcriptional regulators [93]. Other putative mobilizable transposons, such as Tn6104 from strain R20291, contain genes with distant similarity to Tn4451/3 but also carry other accessory genes [83]. The presence of these variants highlights the possible modular nature of these transposons, and the potential for genetic exchange between different mobile genetic elements.

Linezolid is a synthetic antibiotic from the oxazolidinone group that is used to treat serious Gram-positive infections such as pneumonia and skin and deep tissue infections. It is typically an antibiotic of last resort for infections that are resistant to several other antibiotics. Although not used in the routine treatment of C. difficile, a small study indicated that linezolid may protect pneumonia patients from developing CDI [94], however, $C$. difficile resistance to this antibiotic has already been observed [95]. Resistance to linezolid can be mediated by the $c f r$ (chloramphenicol-florfenicol resistance) gene which encodes an RNA methyltransferase that functions by modifying the $23 \mathrm{~S}$ rRNA, thereby conferring resistance to phenicols, 
lincosamides, oxazolidinones, pleuromutilins and streptogramin A antibiotics [96]. The $c f r$ gene is usually carried on plasmids [96] but is chromosomally located in C. difficile, where it appears to be associated with a transposon similar to Tn6218, a novel Tn916-like transposon [95]. The accessory genes of other Tn6218 variants putatively encode resistance to polyketide antibiotics, aminoglycosides (aacA-aphD) and erythromycin (erm(B)) [97]. Again, these variants provide support for the hypothesis that C. difficile may act as a recipient or a donor for antibiotic resistance gene transfer in the microbiota of the gastrointestinal tract.

\section{CDI Treatment and the Threat of Antibiotic Resistance}

Treatment of acute CDI usually involves oral metronidazole or vancomycin as the first-line therapy. Vancomycin and metronizadole are both effective for the treatment of mild infection, while vancomycin is superior in the treatment of severe or recurrent CDI $[98,99]$. Metronizadole is often the preferred therapy for mild to moderate CDI because of its low cost [99]. Fidaxomicin has also been approved for the treatment of CDI and is similar to vancomycin in treatment efficacy, although the high cost of this antibiotic precludes its routine use. However, fidaxomicin is superior to vancomycin in preventing recurrent disease and is often used in the treatment of recurrent infections or for patients with a high relapse risk [99]. Resistance in vivo to vancomycin or metronidazole has not been reported, however, decreased responsiveness to metronidazole for mild to moderate infection has been observed [100]. Despite a lack of resistance to these antibiotics their use in the treatment of CDI remains of concern, primarily because of the continued disruption to the protective microbiota. In addition, there is the possibility that vancomyin use, in particular, will promote resistance and the spread of resistance determinants to other microorganisms, such as Enterococcus species, that may subsequently have important clinical repercussions [101,102].

One of the major concerns in the treatment of CDI is disease recurrence, estimated to occur in up to $30 \%$ of patients following an initial infection but occurring in up to $60 \%$ of patients who have multiple infection episodes [12,32]. Recurrent infection is associated with continued antibiotic use and the failure of the commensal gut microbiota to be restored. For this reason, replenishment of the gut microbiota by fecal microbial transplantation has proven to be highly successful in the treatment of recurrent infection [103] and has provided new insights into the role of microbiota in CDI and in the design of new therapeutic approaches.

In 2013, the CDC published a report naming $C$. difficile as one of the top antibiotic resistant threats to public health because of the role that antibiotic treatment plays in inducing susceptibility to CDI [17]. Although $C$. difficile has not yet developed significant resistance to the antibiotics most used for CDI treatment it is highly likely that these resistance phenotypes will emerge, as has occurred through the use of clindamycin and the fluoroquinolones. The development of vancomycin resistance in C. difficile is deeply concerning at a global level and is more than likely to emerge; after all, vancomycin resistance was reported in Enterococcus species thirty years after the introduction of this antibiotic [104].

Intimately associated with the development of antibiotic resistance in $C$. difficile is the diversity of mobile genetic elements found in this bacterium, which have been identified through functional and bioinformatic studies. Many of these elements encode antibiotic resistance genes and most of these genes are located on genetic elements that are capable of lateral gene transfer. The similarity of these elements 
to those from unrelated bacteria, in addition to their modular nature, suggests that genetic exchange between disparate microorganisms occurs readily. This notion is not surprising since the gastrointestinal niche is an ideal environment for DNA exchange because of the close proximity of bacteria to one another. Evidence in support of this hypothesis has been obtained through in vitro transfer experiments, which clearly show that these elements disseminate via lateral gene transfer events, as discussed earlier. This work also confirms that $C$. difficile can facilitate the movement of various resistance genes and that it may act as both a donor and recipient in this process.

In addition to being intrinsically resistant to some classes of antibiotics, $C$. difficile encodes many specific antibiotic resistance genes or mechanisms, which allow it to proliferate in the gut when these antibiotics are being used for patient treatment. The extended use of the fluoroquinolones, for example, has promoted the worldwide dissemination of BI/NAP1/027 clones that are associated with more severe disease. The fluoroquinolone resistance phenotype of these clones during high clinical fluoroquinolone use promoted their dissemination and transmission compared to fluoroquinolone susceptible strains [50-53]. Clearly, antibiotic use poses many risks for the continued threat of CDI, primarily through the induction of susceptibility in treated patients and in the development and selection of antibiotic resistant $C$. difficile strains.

\section{Conclusions}

C. difficile is the major cause of AAD and a major worldwide health concern particularly in hospitals and aged-care facilities. Community-acquired $C$. difficile infection is also on the rise. A key event preceding $C$. difficile infection is the disruption of normal gastrointestinal microbiota by antibiotics that allows $C$. difficile to proliferate in the gut niche. While resistance to antibiotics currently used to treat C. difficile infection, such as vancomycin and metronidazole, has not been seen clinically, resistance to many other antibiotics has been observed for this pathogen. Some of the resistance genes conferring these advantageous phenotypes are chromosomally encoded and many are located within mobile genetic elements such as conjugative and mobilizable transposons. These mobile genetic elements are often related to similar entities found in other bacterial pathogens, suggesting that they may be derived from a common source and highlighting the importance of horizontal gene transfer of antibiotic resistance between different bacterial genera and species.

The picture emerging of $C$. difficile and antibiotic resistance is clearly one of complexity. The development of antibiotic resistance in this bacterial pathogen is of concern but it is also alarming that this bacterium may act as a reservoir for the acquisition and dissemination of resistance genes to other pathogens that occupy the same host niche. Vigilant and continuing antibiotic stewardship and antimicrobial resistance monitoring are essential if we are to tackle the global health burden of this pathogen and antibiotic resistance.

\section{Acknowledgments}

Research is supported by Project Grants from the Australian National Health and Medical Research Council (NHMRC) and Discovery Grants from the Australian Research Council (ARC). Dena Lyras is supported by an Australian Research Council Future Fellowship. 


\section{Conflicts of Interest}

The authors declare no conflict of interest.

\section{References}

1. Clemente, J.C.; Ursell, L.K.; Parfrey, L.W.; Knight, R. The impact of the gut microbiota on human health: An integrative view. Cell 2012, 148, 1258-1270.

2. McLean, M.H.; Dieguez, D., Jr.; Miller, L.M.; Young, H.A. Does the microbiota play a role in the pathogenesis of autoimmune diseases? Gut 2015, 64, 332-341.

3. McFarland, L.V. Antibiotic-associated diarrhea: Epidemiology, trends and treatment. Future Microbiol. 2008, 3, 563-578.

4. Kyne, L. Clostridium difficile-Beyond antibiotics. N. Engl. J. Med. 2010, 362, 264-265.

5. Asha, N.J.; Tompkins, D.; Wilcox, M.H. Comparative analysis of prevalence, risk factors, and molecular epidemiology of antibiotic-associated diarrhea due to Clostridium difficile, Clostridium perfringens, and Staphylococcus aureus. J. Clin. Microbiol. 2006, 44, 2785-2791.

6. Dial, S. Risk of Clostridium difficile diarrhea among hospital inpatients prescribed proton pump inhibitors: Cohort and case-control studies. Can. Med. Assoc. J. 2004, 171, 33-38.

7. Yearsley, K.A.; Gilby, L.J.; Ramadas, A.V.; Kubiak, E.M.; Fone, D.L.; Allison, M.C. Proton pump inhibitor therapy is a risk factor for Clostridium difficile-associated diarrhoea. Aliment. Pharmacol. Ther. 2006, 24, 613-619.

8. Tennant, S.M.; Hartland, E.L.; Phumoonna, T.; Lyras, D.; Rood, J.I.; Robins-Browne, R.M.; van Driel, I.R. Influence of gastric acid on susceptibility to infection with ingested bacterial pathogens. Infect. Immun. 2008, 76, 639-645.

9. Agastya, G.; West, B.C.; Callahan, J.M. Omeprazole inhibits phagocytosis and acidification of phagolysosomes of normal human neutrophils in vitro. Immunopharm. Immunot. 2000, 22, 357-372.

10. Wandall, J.H. Effects of omeprazole on neutrophil chemotaxis, super oxide production, degranulation, and translocation of cytochrome b-245. Gut 1992, 33, 617-621.

11. Zedtwitz-Liebenstein, K.; Wenisch, C.; Patruta, S.; Parschalk, B.; Daxböck, F.; Graninger, W. Omeprazole treatment diminishes intra- and extracellular neutrophil reactive oxygen production and bactericidal activity. Crit. Care Med. 2002, 30, 1118-1122.

12. Leffler, D.A.; Lamont, J.T. Clostridium difficile infection. N. Engl. J. Med. 2015, 372, 1539-1548.

13. Benson, L.; Song, X.; Campos, J.; Singh, N. Changing Epidemiology of Clostridium difficile-associated disease in children. Infect. Control Hosp. Epidemol. 2007, 28, 1233-1235.

14. Baker, S.S.; Faden, H.; Sayej, W.; Patel, R.; Baker, R.D. Increasing incidence of community-associated atypical Clostridium difficile disease in children. Clin. Pediatr. 2010, 49, 644-647.

15. Rouphael, N.G.; O’Donnell, J.A.; Bhatnagar, J.; Lewis, F.; Polgreen, P.M.; Beekmann, S.; Guarner, J.; Killgore, G.E.; Coffman, B.; Campbell, J.; et al. Clostridium difficile-associated diarrhea: An emerging threat to pregnant women. Am. J. Obstet. Gynecol. 2008, 198, e1-e6.

16. Hensgens, M.P.; Keessen, E.C.; Squire, M.M.; Riley, T.V.; Koene, M.G.; de Boer, E.; Lipman, L.J.; Kuijper, E.J. Clostridium difficile infection in the community: A zoonotic disease? Clin. Microbiol. Infect. 2012, 18, 635-645. 
17. Center for Disease Control and Prevention. Antibiotic Resistance Threats in the United States, 2013; CDC: Atlanta, GA, USA, 2013.

18. Bartlett, J.G. Clostridium difficile: History of its role as an enteric pathogen and the current state of knowledge about the organism. Clin. Infect. Dis. 1994, 18, S265-S272.

19. Borriello, S.P. Pathogenesis of Clostridium difficile infection. J. Antimicrob. Chemother. 1998, 41, 13-19.

20. Voth, D.E.; Ballard, J.D. Clostridium difficile toxins: Mechanism of action and role in disease. Clin. Microbiol. Rev. 2005, 18, 247-263.

21. Kelly, C.P.; LaMont, J.T. Clostridium difficile-More difficult than ever. N. Engl. J. Med. 2008, 359, 1932-1940.

22. Owens, R.C., Jr.; Donskey, C.J.; Gaynes, R.P.; Loo, V.G.; Muto, C.A. Antimicrobial-associated risk factors for Clostridium difficile infection. Clin. Infect. Dis. 2008, S46, S19-S31.

23. Vedantam, G.; Clark, A.; Chu, M.; McQuade, R.; Mallozzi, M.; Viswanathan, V.K. Clostridium difficile infection: Toxins and non-toxin virulence factors, and their contributions to disease establishment and host response. Gut Microbes 2012, 3, 121-134.

24. Jank, T.; Aktories, K. Structure and mode of action of clostridial glucosylating toxins: The ABCD model. Trends Microbiol. 2008, 16, 222-229.

25. Aktories, K.; Wegner, A. Mechanisms of the cytopathic action of actin-ADP-ribosylating toxins. Mol. Microbiol. 1992, 6, 2905-2908.

26. Awad, M.M.; Johanesen, P.A.; Carter, G.P.; Rose, E.; Lyras, D. Clostridium difficile virulence factors: Insights into an anaerobic spore-forming pathogen. Gut Microbes 2014, 5, 579-593.

27. Barra-Carrasco, J.; Paredes-Sabja, D. Clostridium difficile spores: A major threat to the hospital environment. Future Microbiol. 2014, 9, 475-486.

28. Johnson, S.; Adelmann, A.; Clabots, C.R.; Peterson, L.R.; Gerding, D.N. Recurrences of Clostridium difficile diarrhea not caused by the original infecting organism. J. Infect. Dis. 1989, 159, 340-343.

29. Barbut, F.; Richard, A.; Hamadi, K.; Chomette, V.; Burghoffer, B.; Petit, J.C. Epidemiology of recurrences or reinfections of Clostridium difficile-associated diarrhea. J. Clin. Microbiol. 2000, 38, 2386-2388.

30. O’Neill, G.L.; Beaman, M.H.; Riley, T.V. Relapse versus reinfection with Clostridium difficile. Epidemiol. Infect. 1991, 107, 627-635.

31. Tang-Feldman, Y.; Mayo, S.; Silva, J., Jr.; Cohen, S.H. Molecular analysis of Clostridium difficile strains isolated from 18 cases of recurrent Clostridium difficile-associated diarrhea. J. Clin. Microbiol. 2003, 41, 3413-3414.

32. Johnson, S. Recurrent Clostridium difficile infection: A review of risk factors, treatments, and outcomes. J. Infect. 2009, 58, 403-410.

33. Figueroa, I.; Johnson, S.; Sambol, S.P.; Goldstein, E.J.; Citron, D.M.; Gerding, D.N. Relapse versus reinfection: Recurrent Clostridium difficile infection following treatment with fidaxomicin or vancomycin. Clin. Infect. Dis. 2012, S55, S104-S109.

34. Gerding, D.N.; Muto, C.A.; Owens, R.C., Jr. Measures to control and prevent Clostridium difficile infection. Clin. Infect. Dis. 2008, S46, S43-S49. 
35. Lawley, T.D.; Clare, S.; Deakin, L.J.; Goulding, D.; Yen, J.L.; Raisen, C.; Brandt, C.; Lovell, J.; Cooke, F.; Clark, T.G.; et al. Use of purified Clostridium difficile spores to facilitate evaluation of health care disinfection regimens. Appl. Environ. Microbiol. 2010, 76, 6895-6900.

36. Maillard, J.Y. Innate resistance to sporicides and potential failure to decontaminate. J. Hosp. Infect. 2011, 77, 204-209.

37. Rutala, W.A.; Gergen, M.F.; Weber, D.J. Efficacy of different cleaning and disinfection methods against Clostridium difficile spores: Importance of physical removal versus sporicidal inactivation. Infect. Control Hosp. Epidemiol. 2012, 33, 1255-1258.

38. Weber, D.J.; Rutala, W.A.; Miller, M.B.; Huslage, K.; Sickbert-Bennett, E. Role of hospital surfaces in the transmission of emerging health care-associated pathogens: Norovirus, Clostridium difficile, and Acinetobacter species. Am. J. Infect. Control 2010, 38, S25-S33.

39. Sorg, J.A.; Sonenshein, A.L. Bile salts and glycine as cogerminants for Clostridium difficile spores. J. Bacteriol. 2008, 190, 2505-2512.

40. Giel, J.L.; Sorg, J.A.; Sonenshein, A.L.; Zhu, J. Metabolism of bile salts in mice influences spore germination in Clostridium difficile. PLoS ONE 2010, 5, e8740.

41. Buffie, C.G.; Bucci, V.; Stein, R.R.; McKenney, P.T.; Ling, L.; Gobourne, A.; No, D.; Liu, H.; Kinnebrew, M.; Viale, A.; et al. Precision microbiome reconstitution restores bile acid mediated resistance to Clostridium difficile. Nature 2015, 517, 205-208.

42. Lawley, T.D.; Clare, S.; Walker, A.W.; Goulding, D.; Stabler, R.A.; Croucher, N.; Mastroeni, P.; Scott, P.; Raisen, C.; Mottram, L.; et al. Antibiotic treatment of Clostridium difficile carrier mice triggers a supershedder state, spore-mediated transmission, and severe disease in immunocompromised hosts. Infect. Immun. 2009, 77, 3661-3669.

43. Tedesco, F.J.; Stanley, R.J.; Alpers, D.H. Diagnostic features of clindamycin-associated pseudomembranous colitis. N. Engl. J. Med. 1974, 290, 841-843.

44. Bartlett, J.G.; Chang, T.W.; Gurwith, M.; Gorbach, S.L.; Onderdonk, A.B. Antibiotic-associated pseudomembranous colitis due to toxin-producing clostridia. N. Engl. J. Med. 1978, 298, 531-534.

45. Larson, H.E.; Price, A.B.; Honour, P.; Borriello, S.P. Clostridium difficile and the aetiology of pseudomembranous colitis. Lancet 1978, 1, 1063-1066.

46. George, R.H.; Symonds, J.M.; Dimock, F.; Brown, J.D.; Arabi, Y.; Shinagawa, N.; Keighley, M.R.; Alexander-Williams, J.; Burdon, D.W. Identification of Clostridium difficile as a cause of pseudomembranous colitis. Br. Med. J. 1978, 1, 695.

47. Samore, M.H.; Venkataraman, L.; DeGirolami, P.C.; Merrigan, M.M.; Johnson, S.; Gerding, D.N.; Carmeli, Y.; Harbarth, S. Genotypic and phenotypic analysis of Clostridium difficile correlated with previous antibiotic exposure. Microb. Drug Resist. 2006, 12, 23-28.

48. Bartlett, J.G.; Perl, T.M. The new Clostridium difficile—What does it mean? N. Engl. J. Med. 2005, 353, 2503-2505.

49. Bartlett, J.G.; Gerding, D.N. Clinical recognition and diagnosis of Clostridium difficile infection. Clin. Infect. Dis. 2008, S46, S12-S18.

50. Loo, V.G.; Poirier, L.; Miller, M.A.; Oughton, M.; Libman, M.D.; Michaud, S.; Bourgault, A.M.; Nguyen, T.; Frenette, C.; Kelly, M.; et al. A predominantly clonal multi-institutional outbreak of Clostridium difficile-associated diarrhea with high morbidity and mortality. N. Engl. J. Med. 2005, $353,2442-2449$. 
51. McDonald, L.C.; Killgore, G.E.; Thompson, A.; Owens, R.C., Jr.; Kazakova, S.V.; Sambol, S.P.; Johnson, S.; Gerding, D.N. An epidemic, toxin gene-variant strain of Clostridium difficile. N. Engl. J. Med. 2005, 353, 2433-2441.

52. Kuijper, E.J.; Coignard, B.; Tull, P. Emergence of Clostridium difficile-associated disease in north america and europe. Clin. Microbiol. Infect. 2006, S12, 2-18.

53. O'Connor, J.R.; Johnson, S.; Gerding, D.N. Clostridium difficile infection caused by the epidemic BI/NAP1/027 strain. Gastroenterology 2009, 136, 1913-1924.

54. He, M.; Miyajima, F.; Roberts, P.; Ellison, L.; Pickard, D.J.; Martin, M.J.; Connor, T.R.; Harris, S.R.; Fairley, D.; Bamford, K.B.; et al. Emergence and global spread of epidemic healthcare-associated Clostridium difficile. Nat. Genet. 2013, 45, 109-113.

55. Dridi, L.; Tankovic, J.; Burghoffer, B.; Barbut, F.; Petit, J.C. gyrA and gyrB mutations are implicated in cross-resistance to ciprofloxacin and moxifloxacin in Clostridium difficile. Antimicrob. Agents. Chemother. 2002, 46, 3418-3421.

56. Mackin, K.E.; Elliott, B.; Kotsanas, D.; Howden, B.P.; Carter, G.P.; Korman, T.M.; Riley, T.V.; Rood, J.I.; Jenkin, G.A.; Lyras, D. Molecular characterization and antimicrobial susceptibilities of Clostridium difficile clinical isolates from Victoria, Australia. Anaerobe 2015, 34, 80-83.

57. Spigaglia, P.; Barbanti, F.; Mastrantonio, P. Multidrug resistance in European Clostridium difficile clinical isolates. J. Antimicrob. Chemother. 2011, 66, 2227-2234.

58. Garey, K.W.; Salazar, M.; Shah, D.; Rodrigue, R.; DuPont, H.L. Rifamycin antibiotics for treatment of Clostridium difficile-associated diarrhea. Ann. Pharmacother. 2008, 42, 827-835.

59. Curry, S.R.; Marsh, J.W.; Shutt, K.A.; Muto, C.A.; O’Leary, M.M.; Saul, M.I.; Pasculle, A.W.; Harrison, L.H. High frequency of rifampin resistance identified in an epidemic Clostridium difficile clone from a large teaching hospital. Clin. Infect. Dis. 2009, 48, 425-429.

60. O’Connor, J.R.; Galang, M.A.; Sambol, S.P.; Hecht, D.W.; Vedantam, G.; Gerding, D.N.; Johnson, S. Rifampin and rifaximin resistance in clinical isolates of Clostridium difficile. Antimicrob. Agents Chemother. 2008, 52, 2813-2817.

61. Miller, M.A.; Blanchette, R.; Spigaglia, P.; Barbanti, F.; Mastrantonio, P. Divergent rifamycin susceptibilities of Clostridium difficile strains in Canada and Italy and predictive accuracy of rifampin etest for rifamycin resistance. J. Clin. Microbiol. 2011, 49, 4319-4321.

62. Noren, T.; Wullt, M.; Akerlund, T.; Back, E.; Odenholt, I.; Burman, L.G. Frequent emergence of resistance in Clostridium difficile during treatment of $C$. difficile-associated diarrhea with fusidic acid. Antimicrob. Agents. Chemother. 2006, 50, 3028-3032.

63. Noren, T.; Akerlund, T.; Wullt, M.; Burman, L.G.; Unemo, M. Mutations in fusA associated with posttherapy fusidic acid resistance in Clostridium difficile. Antimicrob. Agents Chemother. 2007, 51, 1840-1843.

64. Sebaihia, M.; Wren, B.W.; Mullany, P.; Fairweather, N.F.; Minton, N.; Stabler, R.; Thomson, N.R.; Roberts, A.P.; Cerdeno-Tarraga, A.M.; Wang, H.; et al. The multidrug-resistant human pathogen Clostridium difficile has a highly mobile, mosaic genome. Nat. Genet. 2006, 38, 779-786.

65. He, M.; Sebaihia, M.; Lawley, T.D.; Stabler, R.A.; Dawson, L.F.; Martin, M.J.; Holt, K.E.; Seth-Smith, H.M.; Quail, M.A.; Rance, R.; et al. Evolutionary dynamics of Clostridium difficile over short and long time scales. PNAS 2010, 107, 7527-7532. 
66. Brouwer, M.S.; Roberts, A.P.; Mullany, P.; Allan, E. In silico analysis of sequenced strains of Clostridium difficile reveals a related set of conjugative transposons carrying a variety of accessory genes. Mob. Genet. Elem. 2012, 2, 8-12.

67. Carattoli, A. Plasmids and the spread of resistance. Int. J. Med. Microbiol. 2013, 303, 298-304.

68. Werner, G.; Coque, T.M.; Franz, C.M.; Grohmann, E.; Hegstad, K.; Jensen, L.; van Schaik, W.; Weaver, K. Antibiotic resistant enterococci-tales of a drug resistance gene trafficker. Int. J. Med. Microbiol. 2013, 303, 360-379.

69. Abraham, L.J.; Wales, A.J.; Rood, J.I. Worldwide distribution of the conjugative Clostridium perfringens tetracycline resistance plasmid, pCW3. Plasmid 1985, 14, 37-46.

70. Bannam, T.L.; Yan, X.X.; Harrison, P.F.; Seemann, T.; Keyburn, A.L.; Stubenrauch, C.; Weeramantri, L.H.; Cheung, J.K.; McClane, B.A.; Boyce, J.D.; et al. Necrotic enteritis-derived Clostridium perfringens strain with three closely related independently conjugative toxin and antibiotic resistance plasmids. MBio 2011, doi:10.1128/mBio.00190-11.

71. Ionesco, H. Transferable tetracycline resistance in "Clostridium difficile" (author's transl). Ann. Microbiol. 1980, 131A, 171-179.

72. Wust, J.; Hardegger, U. Transferable resistance to clindamycin, erythromycin, and tetracycline in Clostridium difficile. Antimicrob. Agents Chemother. 1983, 23, 784-786.

73. Hachler, H.; Berger-Bachi, B.; Kayser, F.H. Genetic characterization of a Clostridium difficile erythromycin-clindamycin resistance determinant that is transferable to Staphylococcus aureus. Antimicrob. Agents Chemother. 1987, 31, 1039-1045.

74. Hachler, H.; Kayser, F.H.; Berger-Bachi, B. Homology of a transferable tetracycline resistance determinant of Clostridium difficile with Streptococcus (Enterococcus) faecalis transposon Tn916. Antimicrob. Agents Chemother. 1987, 31, 1033-1038.

75. Farrow, K.A.; Lyras, D.; Rood, J.I. Genomic analysis of the erythromycin resistance element Tn5398 from Clostridium difficile. Microbiology 2001, 147, 2717-2728.

76. Roberts, A.P.; Johanesen, P.A.; Lyras, D.; Mullany, P.; Rood, J.I. Comparison of Tn5397 from Clostridium difficile, Tn916 from Enterococcus faecalis and the CW459tet(m) element from Clostridium perfringens shows that they have similar conjugation regions but different insertion and excision modules. Microbiology 2001, 147, 1243-1251.

77. Clewell, D.B.; Flannagan, S.E.; Jaworski, D.D. Unconstrained bacterial promiscuity: The Tn916-Tn1545 family of conjugative transposons. Trends Microbiol. 1995, 3, 229-236.

78. Roberts, A.P.; Mullany, P. Tn916-like genetic elements: A diverse group of modular mobile elements conferring antibiotic resistance. FEMS Microbiol. Rev. 2011, 35, 856-871.

79. Mullany, P.; Wilks, M.; Lamb, I.; Clayton, C.; Wren, B.; Tabaqchali, S. Genetic analysis of a tetracycline resistance element from Clostridium difficile and its conjugal transfer to and from bacillus subtilis. J. Gen. Microbiol. 1990, 136, 1343-1349.

80. Jasni, A.S.; Mullany, P.; Hussain, H.; Roberts, A.P. Demonstration of conjugative transposon (Tn5397)-mediated horizontal gene transfer between Clostridium difficile and Enterococcus faecalis. Antimicrob. Agents Chemother. 2010, 54, 4924-4926.

81. Roberts, A.P.; Pratten, J.; Wilson, M.; Mullany, P. Transfer of a conjugative transposon, Tn5397 in a model oral biofilm. FEMS Microbiol. Lett. 1999, 177, 63-66. 
82. Brouwer, M.S.; Allan, E.; Mullany, P.; Roberts, A.P. Draft genome sequence of the nontoxigenic Clostridium difficile strain CD37. J. Bacteriol. 2012, 194, 2125-2126.

83. Brouwer, M.S.; Warburton, P.J.; Roberts, A.P.; Mullany, P.; Allan, E. Genetic organisation, mobility and predicted functions of genes on integrated, mobile genetic elements in sequenced strains of Clostridium difficile. PLoS ONE 2011, 6, e23014.

84. Dong, D.; Chen, X.; Jiang, C.; Zhang, L.; Cai, G.; Han, L.; Wang, X.; Mao, E.; Peng, Y. Genetic analysis of Tn916-like elements conferring tetracycline resistance in clinical isolates of Clostridium difficile. Int. J. Antimicrob. Agents 2014, 43, 73-77.

85. Farrow, K.A.; Lyras, D.; Rood, J.I. The macrolide-lincosamide-streptogramin B resistance determinant from Clostridium difficile 630 contains two erm(B) genes. Antimicrob. Agents Chemother. 2000, 44, 411-413.

86. Johnson, S.; Samore, M.H.; Farrow, K.A.; Killgore, G.E.; Tenover, F.C.; Lyras, D.; Rood, J.I.; DeGirolami, P.; Baltch, A.L.; Rafferty, M.E.; et al. Epidemics of diarrhea caused by a clindamycin-resistant strain of Clostridium difficile in four hospitals. N. Engl. J. Med. 1999, 341, 1645-1651.

87. Spigaglia, P.; Carucci, V.; Barbanti, F.; Mastrantonio, P. Ermb determinants and Tn916-like elements in clinical isolates of Clostridium difficile. Antimicrob. Agents Chemother. 2005, 49, 2550-2553.

88. Wasels, F.; Spigaglia, P.; Barbanti, F.; Mastrantonio, P. Clostridium difficile erm(B)-containing elements and the burden on the in vitro fitness. J. Med. Microbiol. 2013, 62, 1461-1467.

89. Wasels, F.; Monot, M.; Spigaglia, P.; Barbanti, F.; Ma, L.; Bouchier, C.; Dupuy, B.; Mastrantonio, P. Inter- and intraspecies transfer of a Clostridium difficile conjugative transposon conferring resistance to MLSB. Microbial Drug Resist. 2014, 20, 555-560.

90. Goh, S.; Hussain, H.; Chang, B.J.; Emmett, W.; Riley, T.V.; Mullany, P. Phage ФC2 mediates transduction of Tn6215, encoding erythromycin resistance, between Clostridium difficile strains. MBio 2013, 4, e00840-e0813.

91. Lyras, D.; Storie, C.; Huggins, A.S.; Crellin, P.K.; Bannam, T.L.; Rood, J.I. Chloramphenicol resistance in Clostridium difficile is encoded on Tn4453 transposons that are closely related to Tn4451 from Clostridium perfringens. Antimicrob. Agents Chemother. 1998, 42, 1563-1567.

92. Abraham, L.J.; Rood, J.I. Identification of Tn4451 and Tn4452, chloramphenicol resistance transposons from Clostridium perfringens. J. Bacteriol. 1987, 169, 1579-1584.

93. Adams, V., Johanesen, P.A., Rood, J.I.; Lyras, D. Mobilisable genetic elements from the clostridia. In Bacterial Integrative Mobile Genetic Elements; Mullany, P., Roberts, A.P., Eds.; Landes Bioscience: Austin, TX, USA, 2013; pp 120-134.

94. Valerio, M.; Pedromingo, M.; Munoz, P.; Alcala, L.; Marin, M.; Pelaez, T.; Giannella, M.; Bouza, E. Potential protective role of linezolid against Clostridium difficile infection. Int. J. Antimicrob. Agents 2012, 39, 414-419.

95. Marin, M.; Martin, A.; Alcala, L.; Cercenado, E.; Iglesias, C.; Reigadas, E.; Bouza, E. Clostridium difficile isolates with high linezolid mics harbor the multiresistance gene cfr. Antimicrob. Agents Chemother. 2015, 59, 586-589.

96. Shen, J.; Wang, Y.; Schwarz, S. Presence and dissemination of the multiresistance gene $c f r$ in gram-positive and gram-negative bacteria. J. Antimicrob. Chemother. 2013, 68, 1697-1706. 
97. Dingle, K.E.; Elliott, B.; Robinson, E.; Griffiths, D.; Eyre, D.W.; Stoesser, N.; Vaughan, A.; Golubchik, T.; Fawley, W.N.; Wilcox, M.H.; et al. Evolutionary history of the Clostridium difficile pathogenicity locus. Genome Biol. Evol. 2014, 6, 36-52.

98. Zar, F.A.; Bakkanagari, S.R.; Moorthi, K.M.; Davis, M.B. A comparison of vancomycin and metronidazole for the treatment of Clostridium difficile-associated diarrhea, stratified by disease severity. Clin. Infect. Dis. 2007, 45, 302-307.

99. Bagdasarian, N.; Rao, K.; Malani, P.N. Diagnosis and treatment of Clostridium difficile in adults: A systematic review. JAMA 2015, 313, 398-408.

100. Pepin, J.; Alary, M.E.; Valiquette, L.; Raiche, E.; Ruel, J.; Fulop, K.; Godin, D.; Bourassa, C. Increasing risk of relapse after treatment of Clostridium difficile colitis in Quebec, Canada. Clin. Infect. Dis. 2005, 40, 1591-1597.

101. Al-Nassir, W.N.; Sethi, A.K.; Li, Y.; Pultz, M.J.; Riggs, M.M.; Donskey, C.J. Both oral metronidazole and oral vancomycin promote persistent overgrowth of vancomycin-resistant enterococci during treatment of Clostridium difficile-associated disease. Antimicrob. Agents Chemother. 2008, 52, 2403-2406.

102. Rice, L.B. The complex dynamics of antimicrobial activity in the human gastrointestinal tract. Trans. Am. Clin. Climatol Assoc. 2013, 124, 123-132.

103. Aas, J.; Gessert, C.E.; Bakken, J.S. Recurrent Clostridium difficile colitis: Case series involving 18 patients treated with donor stool administered via a nasogastric tube. Clin. Infect. Dis. 2003, 36, $580-585$.

104. Levine, D.P. Vancomycin: A history. Clin. Infect. Dis. 2006, S42, S5-S12.

(C) 2015 by the authors; licensee MDPI, Basel, Switzerland. This article is an open access article distributed under the terms and conditions of the Creative Commons Attribution license (http://creativecommons.org/licenses/by/4.0/). 